\title{
A Study on Knowledge Management in Enterprise Information Systems
}

\author{
Shuojia Guo', Chengen Wang ${ }^{2}$, and Xiaochuan Luo ${ }^{2}$ \\ 1 School of Management, Huazhong University of Science and \\ Technology, Wuhan 430074, P.R. China \\ email: nancy0123@vip.163.com \\ 2 Key Laboratory of Process Industry Automation, Northeast \\ University, Shenyang 110004, P.R. China
}

\begin{abstract}
Knowledge is considered as an enterprise's invisible assets. Surviving in today's highly competitive and ever expanding global economy requires efficiently managing corporate knowledge. Increasing requirements for extended enterprises have stimulated the integration of knowledge management $(\mathrm{KM})$ function into ERP systems for knowledge asset management. So far enterprise information systems such as ERP systems are developed and implemented for mainly managing physical assets of an enterprise since 1990s. Due to the fact that both types of assets need to be properly managed, the integration of KM and ERP becomes a strategic initiative for providing competitive advantages to enterprises. This paper discusses how to deploy KM and ERP concurrently in the framework of enterprise information systems, with a discussion of the interaction of $\mathrm{KM}$ and ERP systems in systems perspectives.
\end{abstract}

\section{Introduction}

In the era of global economy, the world-wide business environment has been dramatically changed in recent years which contributed to today's competition in many industry sectors [15]. Enterprise information systems such as ERP systems have been adopted and implemented at a speedy pace to improve competitiveness. In such a highly dynamic environment, enterprises also increasingly recognize that knowledge management is one of the most important factors contributing to business success. In general, an enterprise, especially a high-tech enterprise, has two major types of assets, physical and knowledge assets. Today's enterprises are forced to conduct their business with the help of knowledge management and their competitive edge largely depends on knowledge, expertise, know-how, patents, and innovations.

Please use the following format when citing this chapter:

Guo, S., Wang, C., Luo, X., 2006, in International Federation for Information Processing, Volume 205, Research and Practical Issucs of Enterprise Information Systems, eds. Tjoa, A.M., Xu, L., Chaudhry, S., (Boston:Springer), pp.597-608. 


\subsection{Knowledge Management and Knowledge Management Systems}

Knowledge has been defined slightly different by many authors. For example, Davenport and Prusak [8] argued that knowledge is a mix of experience, values, contextual information, and expert insight that provides a framework for evaluating and incorporating new experiences and information. According to this, although knowledge is related to both data and information; but is neither data nor information.

As knowledge originates and transfers, it is embedded in organizational documents, routines, processes, as well as practices and norms. Knowledge management $(\mathrm{KM})$ is the organizational process for acquiring, organizing, and communicating both explicit and tacit knowledge so that users may use the knowledge to be more effective and productive. $\mathrm{KM}$ systems are information systems designed to collect, code, integrate, disseminate, and facilitate organizational knowledge.

In the last few years, increasing attention has been paid on the $\mathrm{KM}$ issues in organizations. Efficient knowledge management leads to superior business performance such as organizational creativity, operational effectiveness, and quality of products and service [3, 14, and 18]. In decision making processes, decision makers require a combination of different types of data, information, and knowledge. Research shows that KM is useful in ERP [2, 3, and 11]. Currently the research emphasis in the area has been on the KM framework and approaches [5, 10, and 16].

\subsection{ERP and ERP System}

ERP is a system that concentrates on the realization of business integration concepts [13]. The key driving force to implement ERP systems is the need of integrating processes and systems across the global supply chain operation and improving performance and cutting costs $[8,21]$. ERP originates from MRP II (Manufacturing Resource Planning), which in turn, is an extension of MRP (Material Requirement Planning). The key underlying idea of ERP is to achieve a capability of planning and integrating enterprise-wide resources.

A successfully implemented ERP can link all areas of an enterprise including customer relation, manufacturing, human resource, financial management, and distribution with customers and suppliers, and forming a highly integrated system with shared data [17]. Potential benefits include drastic declines in inventory, reduction in working capital, abundant information about what customer wants and needs, along with the ability to view and manage the extended enterprise of customers, suppliers, and alliances as an integrated whole.

\subsection{Concurrently Implementing ERP and KM}

Although ERP and KM systems emphasize different characteristics, the primary goal of the both systems is to improve the competitiveness of enterprises in global 
markets. From practical point of view, KM systems are not preferred to be implemented in isolation but concurrent with numerous subsystems such as PDM, CAD, SCM, and even ERP. A few authors have suggested that it is possible to implement ERP and KM concurrently with ambidextrous results [22]. On the other hand, $\mathrm{KM}$ can be employed through the entire ERP life cycle to support ERP implementation such as feasibility analysis, user requirement analysis, system design, development, maintenance, and testing.

As implementation of two different IT concepts, the key characteristics of ERP and $\mathrm{KM}$ are quite different in their orientation: with ERP systems focusing primarily on managing physical assets and KM systems on innovation and utilization of knowledge assets [6]. In general, ERP defines business processes as standard routines to maximize organizational efficiency. In comparison with the orientation of ERP systems, KM emphasizes on continuous learning at the individual and organizational levels as a complementary approach to improving productivity and efficiency.

This paper is intended to discuss the issues of concurrent implementation of ERP and KM in the framework of enterprise information systems. After discussing the interactions between ERP and KM systems in Section 2, issues related to implementation are discussed in Section 3. Section 4 proposes some ideas on the methods for integrating ERP and KM. Conclusion is provided in Section 5.

\section{Interaction between ERP and KM Systems}

The distinction between information and knowledge not only suggests their different implication and value for organizations, but also suggests that both ERP and KM system are needed in order to provide and leverage the respective values of information and knowledge.

Enterprise information systems such as ERP can provide the information platform for knowledge capturing, storing, sharing, and innovating, since $\mathrm{KM}$ must dependent upon integrating data and information though ERP. KM integrated with ERP can improve the business processes managed by ERP to increase firms' competitive advantages. The interaction between ERP and KM systems are synergistic and of significant importance.

\subsection{Common Goals of ERP and KM Systems}

Despite the different focus of ERP and KM systems, the two systems, to some extent, have common goals. Both ERP and KM aim at improving business processes to achieve better business performance, with tasks based on data, information, and knowledge.

ERP systems emphasize the efficiency of business processes in enterprises. To achieve the goals, ERP systems maintain mechanism for data/information consistency through high degrees of standardization, formalization, and 
specialization. $\mathrm{KM}$ systems devote to the knowledge processes of enterprises such as knowledge creating, storing, transferring, and sharing. In perspectives of enterprises, the ultimate goals of the two systems are helping enterprise survive in the global market by improving their performance. In summary, ERP and KM systems manage the business from the point of views of physical and knowledge assets respectively.

With a proper framework in which ERP and KM can cooperate with each other, an enterprise can benefit from the advantages of ERP and KM and be successful in global competition.

\subsection{Interaction between ERP and KM Systems}

In a given enterprise in which ERP and KM systems are implemented concurrently, the interaction between ERP and KM systems can be discussed from two perspectives: the effects of ERP on $\mathrm{KM}$, and the benefits from $\mathrm{KM}$ for ERP implementation.

ERP systems can provide transaction processing capabilities that help integrate all of a firm's transaction activities. Using such transaction processing information, a firm can plan their activities such as production in which $\mathrm{KM}$ can be useful for a series of activities including transaction processing support [3, 12]. Some ERP products have provided software components for facilitating knowledge management. For example, SAP provides solutions for knowledge management and transfer, which is integrated into an interface to share with various other components of the system.

\subsubsection{Effects of ERP on KM}

ERP includes certain key models of organizational process, and provides a key tool for acquiring information about the day-to-day business activity. ERP also provides a large body of data and information in an enterprise for possible use as knowledge after appropriate processing and integration. Therefore, ERP system becomes a key channel for capturing, exploring, and sharing knowledge.

ERP also changes the way of organizational learning through enabling and facilitating organizational members to innovate. For example, innovations can be made using sophisticated analytical tools rather than simply operating within the limit of pre-defined analysis. The forms of creativity also change and it will consequently change what the organization can learn about its internal business process as well as its environment.

In addition to the changes in organizational learning, implementing ERP will also result in major changes as organizations know more about their business and business processes, which will also make related knowledge available for capturing, utilizing, and sharing. As a result, the knowledge about organizational business processes becomes more widespread as the experience with ERP grows, which eventually makes knowledge management an imperative task. 


\subsubsection{Effects of KM on ERP}

Knowledge related to ERP implementation is facing a number of challenges. First, knowledge may be captured and processed by transient resources only; it will vanish soon after the ERP implementation is complete. Therefore knowledge-carrying objects are not considered perpetual in an organization. Second, traditional practices do not have an explicit process to ensure that the knowledge being captured will be assimilated, verified, and stored for future use. Third, the volume of knowledge being captured may prevent it from being condensed into a single deliverable at the end of implementation. KM system, which can be implemented with ERP, is able to support ERP implementation efficiently as these issues are resolved.

Knowledge management will also make the knowledge transfer between consultants, IT staff, business process engineers, and management possible. Such transfer is characterized by multi-dimensionality and diversity of sources. As an example, an expert in a certain area must have the chance to learn more about other business areas. An IT expert needs more in-depth knowledge about subject areas in the business processes in order to configure ERP systems for better serving the organization's goal.

\section{Systems Perspectives for Integrating ERP and KM}

ERP and KM are the two philosophies for managing business enterprises. The knowledge-based view of enterprises argues that $\mathrm{KM}$ system is the centre of business enterprises and an enterprise's competitive advantage depends upon the effective integration and management of knowledge assets. From another angle, the information processing view considers that ERP is the centre of enterprise management; ERP enhances business performance through minimizing internal and external uncertainties by improving information flow. Although either view has its limitation, however, from systems perspective, they are complementary to each other [24].

Although ERP and KM are based on different management philosophies, ERP and KM systems complement to each other to some extent. ERP system provides a platform for capturing, creating, storing, and sharing knowledge. KM manages both tacit and explicit knowledge that may be acquired through ERP information platform. However, human factor is one of the most important factors in integrating ERP and KM systems since implementing ERP and KM will impact an enterprise's culture and employees. In fact, any ERP or KM initiative without considering human factors will fail. The success of integrating ERP and KM depends upon the active involvement of company employee throughout the organization as well as on their cooperation with the organization's broader business strategy and culture. Social systems are equally important in ERP and KM [4]. It is clear that the integration of ERP and KM should consider the fact that not only technology but also people play an important role. Meanwhile, the complexity of social processes and their importance in promoting collaboration should be considered. 


\section{Integrating ERP and KM}

ERP and KM can be integrated on the basis of existing ERP and KM systems, or a newly developed KM system can be integrated into an existing ERP system. In the first approach, the relationship between ERP and KM is corporation. In the second approach, a KM system is integrated into an ERP system in terms of modules. The first approach is generally considered as a common approach.

\subsection{Integrating Existing ERP and KM}

It is usual that both ERP and KM are provided by different vendors and both are stand-alone systems. Integrating these two separate systems can provide an enterprise with better business performance. With the integration, the system can manage physical as well as knowledge assets for achieving competitive advantages than ever before.

From the enterprise's point of view, managing both types of enterprise assets is highly desirable. Although ERP and KM emphasize different types of assets respectively, the integration would satisfy the requirement of systematic management (Figure 1)

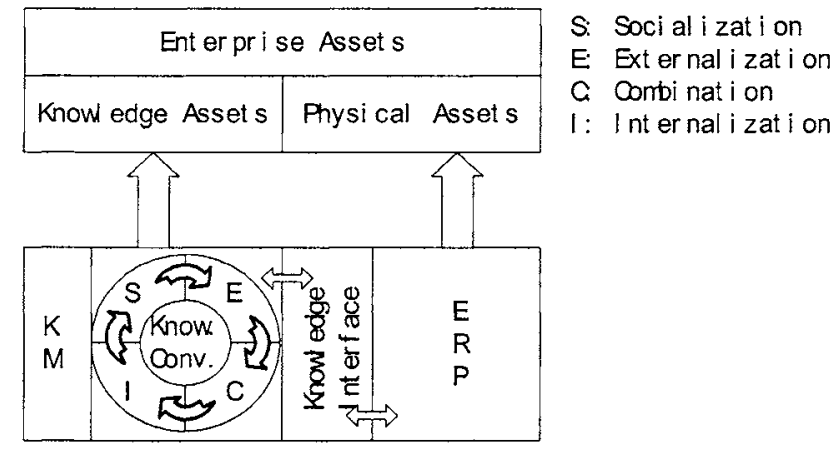

Fig. 1. General method for integrating ERP and KM

\subsubsection{Knowledge interface between ERP and KM}

According to the functions performed, there exist two types of knowledge interfaces between ERP and KM. Knowledge interfaces are the software brokers that transfer knowledge from ERP to KM or from KM to ERP. In other words, knowledge interfaces are the channels though which knowledge flows between ERP and KM. Therefore the knowledge interfaces play important roles in incorporating $\mathrm{KM}$ and ERP (Figure 2). Also there are two knowledge circles such as learning circle and innovation circle. As ERP requests knowledge for business processes, ERP employs 
the methods provided by the knowledge interface to obtain knowledge. As the KM requests operation knowledge, $\mathrm{KM}$ uses the knowledge interface to interact with ERP. In general, according to its function, knowledge interfaces can be classified into K-Discovery, K-Classifying, K-Storage, K-Identifying, and K-Indexing.

\section{Knowledge interface from ERP to $K M$}

K-Discovery: It has the methods to access the data from ERP. Also, it will discover knowledge from ERP process data with information context.

K-Classifying: It has the methods to categorize knowledge according to the type of knowledge and the domain context which the knowledge belongs to.

K-Storage: It has the methods to save knowledge and knowledge context to the knowledge base. It also maintains the linkage between knowledge and its context.

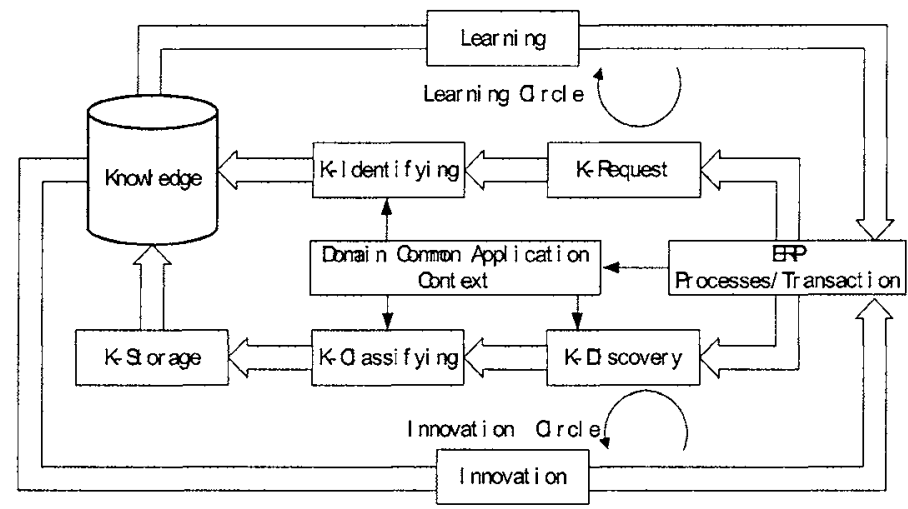

Fig. 2. Knowledge transfer process in incorporation environment of ERP and KM

\section{Knowledge interface from KM to ERP}

K-Identifying: It provides users with the methods to send knowledge request, and transfers the request with its context into query on knowledge base.

K-Indexing: It has the methods to interact with knowledge base engine based on the query commands given by K-Identifying.

In mining knowledge from ERP, two factors to be considered are the objective of knowledge mining such as finding-driven knowledge mining and validationdriven knowledge mining, and the methods of knowledge description and identification.

In general, knowledge in ERP is characterized by multi-factoring, nonlinear, and non-uniform. The following steps can be used to discover knowledge in ERP. Let $F$ represent knowledge field, $K(F)$ represent knowledge set in knowledge field $F$, $D(F)$ databases in ERP with $F$. The elements in $K(F)$ are based on the knowledge description derived from $D(F)$. 
Step 1. Eliminate redundant features using non-correlation features in rough set theory $[19,26]$; obtain databases $D_{R}(F)$ for knowledge discovery. k-nearest neighbor method is then used. First, each sample $x$ in $D(F)$ is considered as a group, according to the criteria of nearest neighbor method, $\mathrm{k}$ neighbors of $x$ are tested. The distance between two sample $x$ and $y$ is defined as (if $x$ and $y$ are $n$ dimensional)

$$
d(x, y)=\sqrt{\sum_{i=1}^{n}\left(x_{i}-y_{i}\right)^{2}}
$$

If $d_{\min }$ is the distance criterion, the samples, with distances less than $d_{\min }$, belong to the same cluster.

Step 2. Determine the correlation factors between parameters using PCA (principal component analysis) [25].

Let matrix $\boldsymbol{X}$ formed by $m n$-dimension sample vector,

$$
X_{m \times n}=\left[\begin{array}{cccc}
x_{11} & x_{12} & \cdots & x_{1 n} \\
x_{21} & x_{22} & \cdots & x_{2 n} \\
\vdots & \vdots & \cdots & \vdots \\
x_{m 1} & x_{m 2} & \cdots & x_{m n}
\end{array}\right]
$$

Consider $m$ vectors from linear combination of $n$-dimension vector $\left\{x_{1}, x_{2}, \cdots, x_{n}\right\}$,

$$
y_{i}=\sum_{i=1}^{n} a_{i} x_{i} \quad i=1,2, \cdots, m \quad m \leq \min (m, n)
$$
data.

$y_{i}(i=1,2, \ldots, m)$ can substitute matrix $\boldsymbol{X}$ to reveal the knowledge with original

Step 3. Estimate knowledge by $k$-fold cross validation method. The data set $y_{i}$ $(i=1,2, \ldots, m)$ is divided into $k$ subsets, and the method is repeated $\mathrm{k}$ times. Each time, one of the $\mathrm{k}$ subsets is used as the test set and the other $\mathrm{k}-1$ subsets are put together to form a training set. Then the average error across all $\mathrm{k}$ trials is computed.

\subsubsection{Integration framework}

ERP systems have the capability of managing an enterprise' physical resources, while KM provides the mechanism to manage the knowledge resources. From the point of views of knowledge creation and innovation, knowledge management is emphasized in two aspects of ERP systems, i.e., business transactions and the related data that are collected and managed by ERP (see Figure 3 ). The incorporation of KM and ERP takes place in these two aspects.

Although ERP and KM perform their respective tasks and functions, knowledge interfaces are needed for information and knowledge sharing. With such interfaces, KM systems identify business process in ERP systems, make knowledge requests, 
and implement knowledge discovery, classifying, and storage based upon the information provided by ERP.

$\mathrm{KM}$ systems carry out K-discovery and K-identifying with the information contexts that are provided by ERP. ERP staff or those business processes within ERP systems can obtain knowledge by request with certain contexts. In this process, knowledge interface and domain common application context are considered important for linking KM system and ERP system to achieve information and knowledge sharing.

Adapting to the knowledge transfer processes in business enterprises, knowledge management has the function of transferring both explicit and tacit knowledge. KM systems are not only involved with organizational knowledge resides in the business process managed by ERP, but also individual knowledge that is partially managed by ERP. Therefore, ERP system platform is needed for implementing $\mathrm{KM}$ systems for knowledge management, which is one of the key components of enterprise management. 


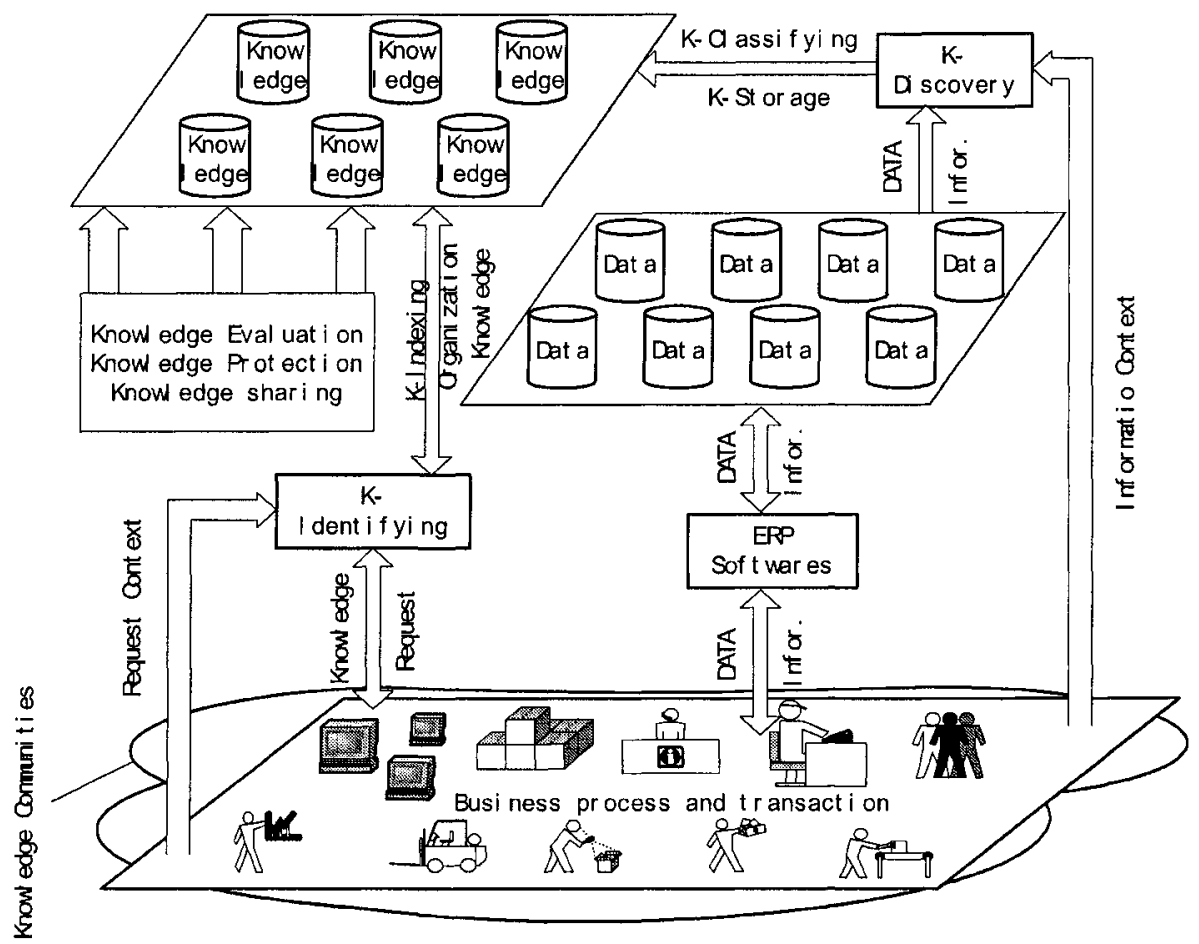

Fig. 3. A framework for integrating ERP and KM

\subsection{Integrating $\mathrm{KM}$ into ERP}

ERP system has the capability of managing physical assets within an enterprise. However, ERP do not manage the knowledge in an enterprise. Due to the differences between ERP and KM, it is not easy to take advantage of integrating KM and ERP by simply adding a KM module into an ERP system. It is obvious that KM has its own purpose compared with that of ERP; to some extent such purposes may be conflicting to each other. For example, KM emphasizes the flexibility in business routine, whereas ERP focuses on the standardization of business routines. In integrating $\mathrm{KM}$ into $\mathrm{ERP}$, changes are needed in ERP to facilitate $\mathrm{KM}$ implementation. Such changes include knowledge base management, knowledge presentation, etc. As a module in an ERP system, KM in general can support ERP for better decision making function. KM can capture knowledge, transfer tacit knowledge to explicit knowledge, and help use or reuse knowledge for ERP purpose. The future generation ERP may include a KM module through achieving trade-off between their contradictions based on two managerial philosophies. 


\section{Conclusions}

Enterprises world wide are facing increasing competition in the knowledge economy era. To be competitive and successful, it is imperative for enterprises to renovate their enterprise information systems such as ERP and integrate knowledge management function. Future generation ERP systems with knowledge management capacity will be more responsive to the changes in global business environment.

An enterprise has two types of important assets: physical and knowledge assets that are managed by ERP and KM systems respectively. As a result, implementing both ERP and KM is highly desirable. From enterprises' point of view, ERP and KM systems should be integrated for competitive advantages. Due to the fact that the objectives and characteristics of ERP and KM are different to each other, the integration involved is a complicated process. The paper discusses the issue of jointly implementing ERP and KM systems. The interaction between ERP and KM systems is also analyzed in systems perspectives.

\section{References}

1. P. Adler, B. Goldoftas, and D. Levine, Flexibility versus Efficiency? A Case Study of Model Changeovers in the Toyota Production System, Organization Science 10, 43-68 (1999). 2. C. Ash and J. Burn, A Strategic Framework for the Management of ERP Enabled Ebusiness Change, European Journal of Operational Research, 146, 374-387 (2003).

3. E. Bendoly, Theory and Support for Process Frameworks of Knowledge Discovery and Data Mining from ERP Systems, Information \& Management 40, 639-647 (2003).

4. G. Bhatt, Knowledge Management in Organizations: Examining the Interaction between Technologies, Techniques, and People, Journal of Knowledge Management 5(1), 68-75 (2001).

5. N. Bolloju, M. Khalifa, and E. Turban, Integrating Knowledge Management Into Enterprise Environments for the Next Generation Decision Support, Decision Support Systems 33, 163$176(2002)$.

6. R. Chan, Knowledge Management for Implementing ERP in SMEs, SAPPHIRE, (1999), pp. 21-39.

7. T. Davenport, Mission Critical: Realizing the Promise of Enterprise Systems (Boston, MA: Harvard Business School Press, 2000).

8. T. Davenport and L. Prusak, Working Knowledge: How Organizations Manage What They Know (Boston, MA: Harvard Business School Press, 1998).

9. K.K. Konstantinos, M. Konstantinos, and P. Oannis, Knowledge Management in Enterprises: A Research Agenda, edited by D. Karagiannis and U. Reimer, PAKM-LNAI 2569, (2002), pp. 37-48.

10. G. Gable, J. Scott, and T. Davenport, Cooperative ERP Life-cycle Knowledge Management. Proceedings of the Ninth Australasian Conference on Information Systems, Sydney, Australia, (1998), pp. 227-240.

11. S. Huin, L. Luong, K. Abhary, Knowledge-based Tool for Planning of Enterprise Resources in ASEAN SMEs, Robotics and Computer Integrated Manufacturing 19, 409-414 (1999). 
12. M. Kennerley and A. Neely, Enterprise Resource Planning: Analyzing the Impact, Integrated Manufacturing Systems 12(2), 103-113 (2001).

13. H. Klaus, M. Rosemann, and G. Gable, What is ERP? Information Systems Frontiers 2(2), 141-162 (2000).

14. G. Krogh, K. Ichijo, and I. Nonaka Enabling Knowledge Creation (Oxford University Press, 2000).

15. H. Li and L. Li, Integrating Systems Concepts into Manufacturing Information Systems, Systems Research and Behavioral Science 17, 135-147 (2000).

16. Y. Malhotra, Knowledge Management and Business Model Innovation (Idea Group Publishing, 2001).

17. K. Mertins and R. Jochem, Architectures, Methods and Tools for Enterprise Engineering, International Journal of Production Economics, in press, (2005).

18. I. Nonaka, A Dynamic Theory of Organizational Knowledge Creation, Organization Science, 5(1), 14-37 (1994).

19. G. Qiu, H. Li, L, Xu, and W. Zhang, A Knowledge Processing Method for Intelligent Systems Based on Inclusion Degree, Expert Systems 20(4), 187-195 (2003).

20. S. Regan, J. Harhen, J. Browne, and M. O'Kelly, The Design of A Microcomputer-based Net Change MRP System, Computers in Industry 4, 243-252 (1983).

21. M. Subramaniam, C. Tan, and W. Welge, Knowledge Management and Data Mining for Marketing, Decision Support Systems 31, 127-137 (2001).

22. C. Soh, S. Kien, and J. Yap, Cultural Fits and Misfits: Is ERP A Universal Solution? Communications of the ACM 43, 47-51 (2000).

23. M. Tushman and C. O'Reilly, Winning Through Innovation (Boston, MA: Harvard Business School Press, 1997).

24. E. Van Stijn, and A. Wensley, Organizational Memory and the Completeness of Process Modeling in ERP Systems: Some Concerns, Methods and Directions for Future Research, Business Process Management Journal 7(3), 181-194 (2001).

25. L. Xu and L. Li, Complementary Opposition As A Systems Concept, Systems Research 6(2), 91-101 (1989).

26. S. Xu, L. Xu, and X. Chen, Determining Optimum Edible Films for Kiwifruits Using an Analytical Hierarchy Process, Computers and Operations Research 30(6), 877-886 (2003).

27. M. Zhang, L. Xu, W. Zhang, and H. Li, A Rough Set Approach to Knowledge Reduction Based on Inclusion Degree and Evidence Reasoning Theory, Expert Systems 20(5), 297-303 (2003). 